\title{
Boštjan Bajec, Eva Boštjančič, Sara Tement \\ ČLOVEK, DELO IN ORGANIZACIJA: Pregled psiholoških področij in perspektiv \\ Ljubljana, Znanstvena založba Filozofske fakultete, 2016
}

Knjiga je pomembna za različne akterje (študente, strokovnjake, ki gradijo kariero na tem področju, zaposlene v kadrovskih oddelkih, izobraževalce) in bi jo potrebovali že pred 20 leti, a do danes ni bilo prave možnosti, da bi se lotili sistematičnega pregleda področij, ki jih pokriva psihologija dela in organizacije.

Pisati monografijo o preteklih in hkrati o aktualnih spoznanjih, tako o mednarodnih kot o slovenskih, o tujih in domačih praktičnih primerih ni lahko, saj se področje dela nenehno spreminja: opušča se osemurni delovnik, delo vedno bolj zajeda prosti čas, ruši se meja med delom in družino, sodobna tehnologija prodira na vsa področja delovanja, delovna sila se stara ...

Potreba po novih raziskavah je velika tako na strani znanosti, ki se trudi odgovoriti na vprašanje, kako sodobni pristopi ter spremembe $\mathrm{v}$ delovnem in družbenem okolju vplivajo na zaposlenega, kot na strani praktikov, ki iščejo pristope, s katerimi bo človek v delovnem okolju čim bolj učinkovit in hkrati zadovoljen.

Delo poskuša zaobjeti večino ključnih področij psihologije dela in organizacije, ki je aplikativna veda in katere predmet raziskovanja so posameznik in njegovo vedenje v delovnem okolju ter z njim povezana dogajanja. Psihologija dela in organizacije je znanost, ki uporablja enako stroge postopke raziskovanja, kot jih lahko najdemo na drugih področjih znanstvenega raziskovanja (Muchinsky, 2006). Bajec v knjigi poudarja, da je psihologija dela in organizacije bolj usmerjena $\mathrm{v}$ uporabo znanstvenih spoznanj in manj v uporabo primerov dobrih praks.

Avtorji v delu prepletajo teorijo s prakso - bralec lahko v vsakem izmed devetih poglavij sledi sistematičnemu pregledu, od pomembnih zgodovinskih mejnikov nastanka in razvoja psihologije dela do pregleda motivacijskih teorij, teorij vodenja pa vse do procesov iskanja in izbora kadrov, ocenjevanja uspešnosti ter mejnih in hkrati komplementarnih področij, ki si s psihologijo dela v teoriji in praksi delijo osnovne pojme, pristope, metode.

Svoja razmišljanja dopolnjujejo z rezultati in spoznanji številnih domačih ter tujih raziskav s področja psihologije dela, kadrovske in organizacijske psihologije. Teoretične modele podkrepijo s spoznanji iz prakse, ki temeljijo na znanstvenih metodah zbiranja in 
obdelovanja podatkov. Slikovni prikazi, preglednice in primeri omogočajo, da je besedilo razumljivo in nazorno tudi za tiste, ki se na karierno pot šele odpravljajo.

V prvem poglavju Boštjan Bajec umesti ter opredeli psihologijo dela in organizacije, tako znotraj znanosti na splošno kot tudi znotraj psihološke vede. V Sloveniji na tem področju deluje 22 odstotkov psihologov, ki jih povezujejo skupna znanja, raznovrstne delovne izkušnje in kompetence. Za prihodnost pa pobudo pri urejanju tega področja počasi prevzema certifikat Europsy. Bajec omenja tri ključne vrednote, ki vodijo psihologijo dela in organizacije - zavezanost znanosti, zavezanost koristi ter zavezanost ravnotežju med ljudmi in organizacijo - ki se kasneje (tudi v naslednjih poglavjih) pojavljajo kot implicitne mere odličnosti na vseh obravnavanih področjih.

Če želimo negovati področje tudi v prihodnje, je pomembno, da se ozremo v preteklost. Bajec v drugem poglavju na zanimiv in pregleden način predstavi ključne mejnike, ki so oblikovali področje. Razmišlja pa tudi o prihodnosti te vede, ki jo vidi kot hkratno opazovanje pojavov na različnih organizacijskih ravneh, pospešeno rast števila mednarodnih primerjav in globalnih raziskav področja, intenzivno analiziranje odnosov med različnimi deležniki kot tudi obravnavo in analiziranje velike količine podatkov, raziskovanje integracije priseljencev in njihovih potomcev, proučevanje učinka vdora $v$ zasebnost, povečano zanimanje za humanizacijo novih oblik dela ...

Sledita poglavji o vsebinah, ki so potrebne za znanstveno in praktično delo psihologov. Tretje poglavje je namenjeno predstavitvi razlik med znanstvenim in neznanstvenim raziskovanjem, saj je strokovnjak (pogosto prav psiholog) na delovnem mestu, čeprav se ukvarja s praktičnimi problemi, dolžan preverjati učinkovitost svojih posegov, zato mora obvladati osnovne raziskovalne metode. Že oblikovanje raziskovalnega vprašanja je lahko ključno - ali bomo le poskušali opisati določeno situacijo, iskali razlago za opazovani pojav, bomo napovedovali izbrano vedenje ali bomo morda sledili spreminjanju določene ravni odnosov. Beremo lahko tudi o lastnostih dobrih merskih instrumentov, različnih načinih zbiranja podatkov, o uporabi raziskovalnih metod.

Četrto poglavje povzema ključne zakone in akte, ki urejajo pristojnosti in odgovornosti delovanja psihologov ter tudi drugih strokovnjakov v vsakodnevni praksi v delovnih organizacijah. Logično nadaljevanje je poglavje o etičnih okvirih dela psihologov v organizacijah. Eva Boštjančič se dotakne pojmov, kot so etika, morala, integriteta, ugled, odgovornost, etični kodeks, ki naj bi jih pri delu upošteval vsak psiholog (ali drug strokovnjak na področju dela $\mathrm{z}$ ljudmi), ki lahko dnevno prehaja med različnimi vlogami - deluje kot svetovalec, opazovalec, izobraževalec, razsodnik, preiskovalec, izpraševalec, organizator, model. Med uporabnimi informacijami najdemo tudi primer pisnega obveščenega soglasja, ki ga mora podpisati vsak, preden vstopi v selekcijski ali kateri drug postopek, v katerem se obdelujejo njegovi osebni podatki.

V drugem delu knjige so zbrana poglavja, ki jih vsebinsko razdelimo v zaključene celote. Prvo od njih je poglavje o psihologiji dela, ki prinaša teoretičen pogled na značilnosti dela in možne rezultate oziroma posledice dela, s katerimi so povezane posamezne značilnosti. 
Ukvarja se predvsem z vprašanjem, kako delo prilagoditi zaposlenemu, ter z razmerjem med značilnostmi dela in osebnostnimi značilnostmi zaposlenih, ki ostaja eden glavnih vidikov napovedovanja vedenja, stališč in čustvenih odzivov pri delu (Arnold idr., 2010), med katerimi se $\mathrm{v}$ praksi najpogosteje omenjata delovna zavzetost in organizacijska pripadnost.

Naslednji poglavji predstavita ključna vprašanja znanstvenega proučevanja dveh področij. Poglavje o kadrovski psihologiji poveže v celoto analizo dela, iskanje in selekcijo kadrov, ocenjevanje delovne uspešnosti, razvoj kadrov ter karierno orientacijo. V poglavju Organizacijska psihologija pa Eva Boštjančič in Sara Tement predstavita delovno organizacijo in psihološke teorije, procese ter manjše organizacijske enote (delovne skupine in time), s pomočjo katerih lahko opišemo dogajanje $\mathrm{v}$ organizaciji. Za bralca bo zanimivo poglavje o merjenju delovne uspešnosti, saj je to danes $\mathrm{v}$ praksi vse prepogosto prepuščeno odločanju vodij, ki pa nimajo ustreznega teoretičnega znanja za oblikovanje motivacijskega modela nagrajevanja.

V sklepnem poglavju so predstavljena sorodna področja psihologije dela, ki so se oblikovala zaradi razvojnih, političnih, ekonomskih in socialnih potreb, ter narava določenih poklicev oz. delovnih področij. Poddiscipline, kot na primer vojaška psihologija ali humanitarna psihologija dela, slonijo na spoznanjih osnovne vede, pri čemer pa je predmet raziskovanja za vsako poddisciplino usmerjen v ključne izzive, ki jih ponuja in potrebuje posamezno podpodročje.

Monografija odpira vrsto vprašanj, vendar pa odgovori le na osnovna. Bralec bo svojo radovednost potešil do te mere, da bo skozi knjigo spoznal večino bazičnih, splošno uveljavljenih teorij ter metod psihologije dela in organizacije, za bolj poglobljen študij ali raziskovanje posameznega področja pa se bo moral še vedno ozreti po literaturi v tujih jezikih.

Besedilo služi kot izhodišče in vabi k nadaljevanju dela. Slovenski strokovnjaki kot tudi študenti si želijo, da bi lahko temeljna področja psihologije dela in organizacije - psihologijo dela, kadrovsko psihologijo, organizacijsko psihologijo - spoznavali tudi v slovenščini ter tako osvajali in v praksi uporabljali tudi ustrezno slovensko izrazoslovje. Da ne bomo več govorili o teamih, temveč o timih, da ne bomo okorno prevajali državljanskega vedenja, temveč uporabljali vedenje $\mathrm{v}$ korist organizacije, da bomo govorili o spretnostih in ne o »skilsih «, o virih in ne »resursih «.

Po mnenju recenzenta (Bucik, 1997) je delo jezikovno in sporočilno jasno, opremljeno z obilico znanstvenih in strokovnih virov, zato je monografija primerna za vsakega študenta, znanstvenika ali praktika, ki se študijsko ali strokovno srečuje z izzivi psihologije dela in organizacije. 


\section{LITERATURA}

Arnold, J., Randall, R., Patterso, F., Silvester, J., Robertson, I., Cooper, C., ... Den Hartog, D. N. (2010). Work psychology: Understanding human behaviour in the Workplace. Harlow: Prentice Hall. Bucik, V. (1997). Osnove psihološkega testiranja. Ljubljana: Filozofska fakulteta.

Muchinsky, P. M. (2006). Psychology applied to work. Belmont: Wadsworth.

Eva Boštjančič 